\title{
Pfeiffer's type of acrocephalosyndactyly in two families
}

\author{
JOSEF VANĚK AND FRANTIŠEK LOŠAN \\ From the Clinic of Orthopaedics, Medical Faculty of Charles University, and the Department of Medical \\ Genetics, County Hospital, Plzěn, Czechoslovakia
}

SUMmaRY Two additional families with Pfeiffer's syndrome are reported in which the wide variability of gene expression is demonstrated.

The syndromes of acrocephalosyndactyly (ACS) and acrocephalopolysyndactyly (ACPS) are marked by extraordinary variability of expression. The Pfeiffer type of ACS that we are going to deal with was delineated in $1964 . .^{1}$ It has an autosomal dominant mode of transmission and is very rare.

\section{Case reports}

FAMILY W (FIG 1)

Case 1 (III-1), the proband, was a 7-year-old boy, born at 32 weeks' gestation by breech presentation. Birthweight was $1800 \mathrm{~g}$ and it was the mother's first pregnancy. The most striking finding was the lateral deviation of the thumbs and medial one of the big toes (figs $2 \mathrm{a}, 3 \mathrm{a}$ ). The 2 nd to 5 th fingers showed brachymesophalangy and the little fingers Received for publication 28 October 1981

\section{Family W}

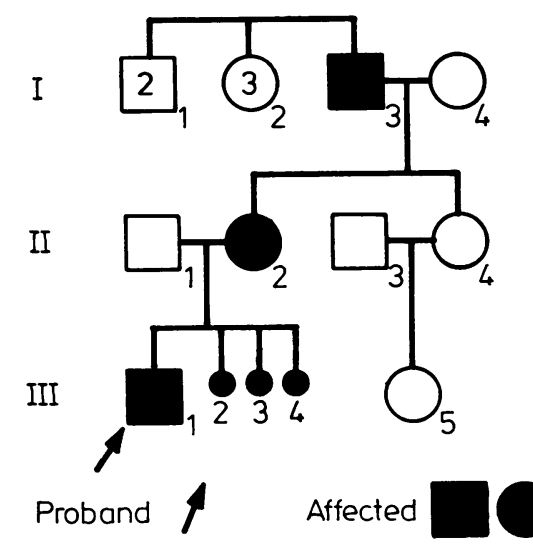

FIG 1 Pedigrees of families $W$ and $K$

Abortion clinodactyly. Syndactyly was not persent on the hands or feet. The face (fig $4 \mathrm{a}$ ) and the neurocranium were without any apparent abnormalities, although complete disappearance of the sagittal suture was reported at the first $x$-ray examination performed at the age of 5 . Impressions of gyri were more apparent.

Case 2 (II.2) was the mother of the proband aged 35 years. She had had spontaneous abortions of her $2 \mathrm{nd}, 3 \mathrm{rd}$, and 4 th pregnancies, the causes of which were unknown. The proximal phalanges of the thumbs and the middle phalanges of the fingers were short (fig 2b). Similar findings, but with symphalangism, were present on the toes (fig $3 \mathrm{~b}$ ). The head was normal (fig 4b).

Case $3(I \cdot 3)$ was the father of the proband's mother, aged 63 years. He refused $x$-ray examination, but the physical appearance of his hands and feet

\section{Family K}

I

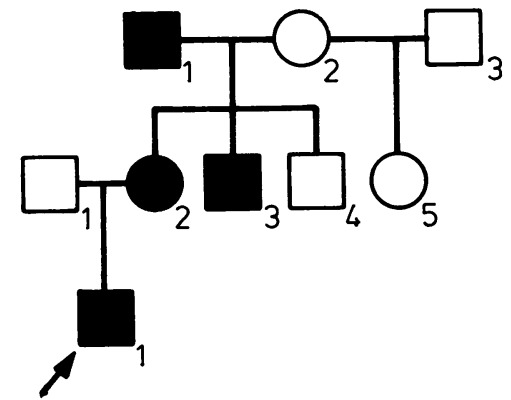




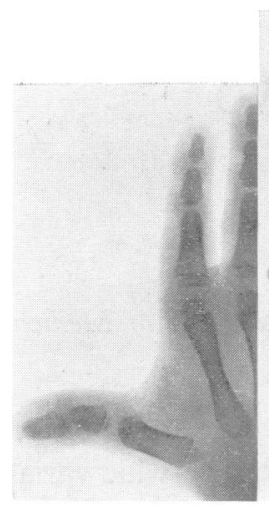

(a)
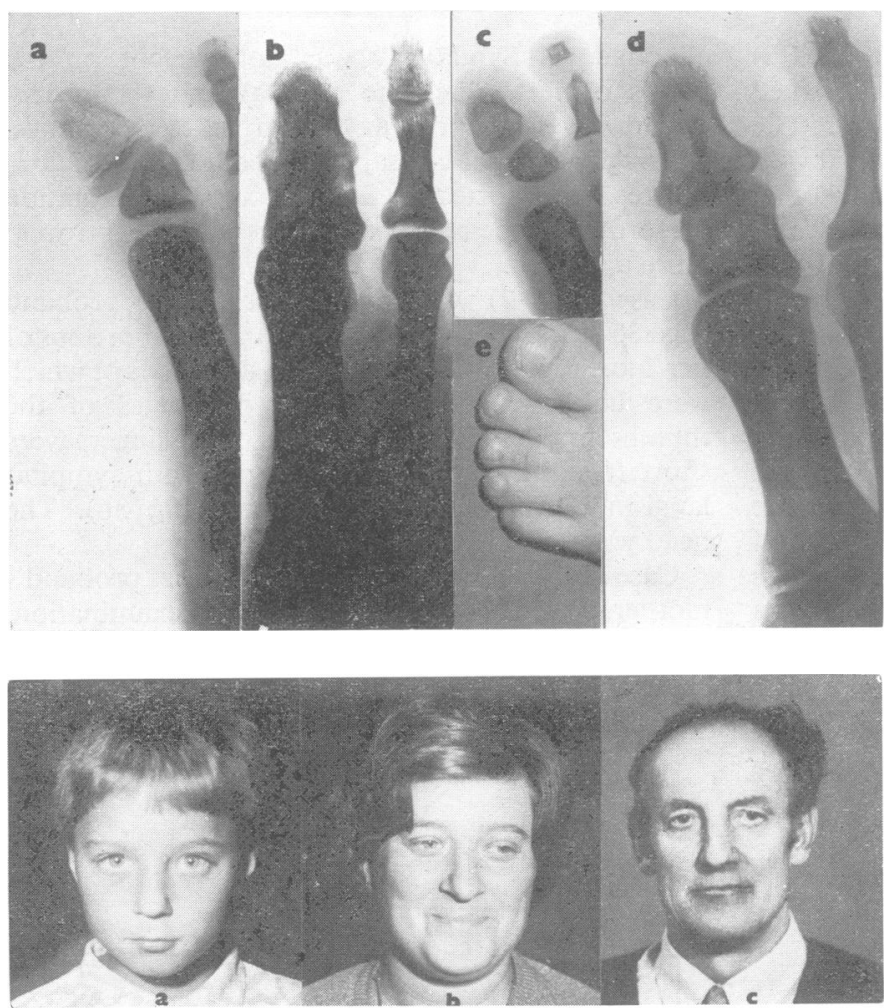

FIG $2 X$-rays of thumbs and index fingers: (a) case 1, (b) case 2, (c) case 5, (d) case 6. In the proximal phalanges of the thumbs great variability of deformities is seen: (a) trapezoidal deformity, $(b)$ deformity of the distal end only, $(c, d)$ minimal shortening. Distal phalanges are wider in (a), shorter in (c), and normal in (b) and (d). Brachymesophalangy is present in all fingers of all the cases, but only the index fingers show significant variability: distal symphalangism in (c) and deformity of the basis in $(d)$.

FIG $3 \quad X$-rays of big and 2nd toes: (a) case $1,(b)$ case $2,(c)$ case $4,(d)$ case 5. A common lesion is widening of the phalanges of the big toes and in $(d)$ of the first metatarsal also. The proximal phalanges may be trapezoidal $(a, c)$, short $(d)$, or short with symphalangism (b). Brachymesophalangy of toes was found in all five patients. The 2nd toes as well as the others show variability from simple shortening of the middle phalanges (a), to shortening with symphalangism $(b$, distal; c, proximal and distal). (e) Photograph of the toes of case 4. Partial skin syndactyly between 2nd-4th toes and broad big toe.

FIG 4 Faces of (a) case 1, (b) case 2, (c) case 3. Normal findings in $(a)$ and $(b)$, wide nose bridge and hypertelorism in $(c)$. was the same as in his daughter. Slight abnormalities were seen on his face (fig 4c).

All three individuals were of normal intelligence.

\section{FAMILY K (FIG 1)}

Case 4 (III-1), the proband, was a 3-year-old boy born of the first and only pregnancy. Delivery of the mature fetus was uncomplicated and psychomotor development has been normal. The findings in the hands were the same as in case 1 and also in the big toes (fig 3c). The middle phalanges of the 2 nd to 5 th toes showed no ossification. Syndactyly was only partial (fig 3e). The nose was short, its tip being turned upwards.

Case 5 (II -2) was the mother of the proband aged 22 years. She spoke with a nasal twang but had no palatoschisis. She was inclined to criminal behaviour and was sentenced several times. She was of normal 


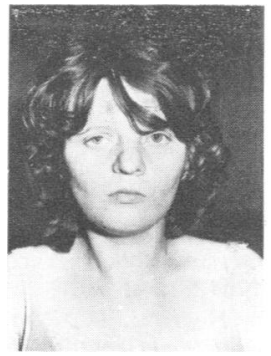

FIG 5 Face of case 5. Slight asymmetry of the face with broad and short nose.
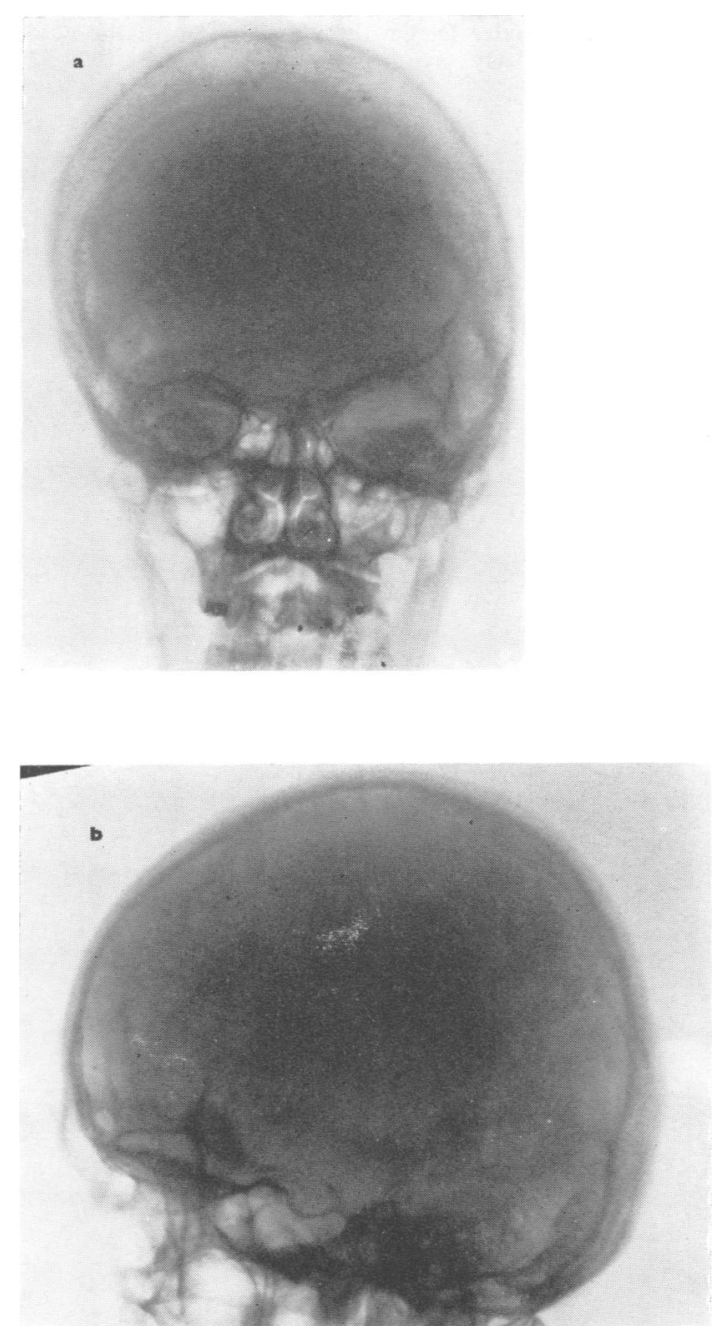

FIG 6 Frontal (a) and lateral (b) $x$-ray of the skull of case 5: brachyturricephaly and asymmetry. Sutures are persisting.

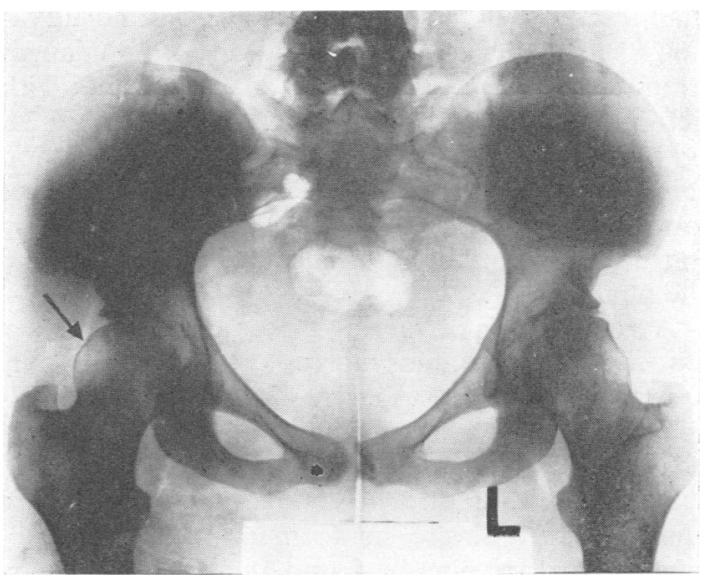

FIG $7 X$-ray of the pelvis of case 5. Bilateral coxa valga with a defect on the lateral side of the left head and irregularity of the cortical line in the same area of the right head (arrow).

intelligence. Both phalanges of the thumbs* and the proximal phalanges of the big toes were short (figs $2 c, 3 d$ ). In the fingers and other toes there was brachymesophalangy and symphalangism with the exception of the 3 rd to 5 th fingers. There was also synostosis between the os calcaneum and the os cuboides and incomplete syndactyly between the 2nd and 3rd toes. The nose was similar to that of her son, case 4. Craniofacial asymmetry and brachyturricephaly are shown in figs 5 and $6 a$ and b, respectively. There was lumbar hyperlordosis, coxa valga, and deformity of the left femoral head (fig 7).

Case 6 (II-3) was the brother of the proband's mother, aged 17. He had minimal shortening of the proximal phalanges of the thumbs* and brachymesophalangy of the fingers (fig $2 \mathrm{~d}$ ). There was a larger skin fold between the 2 nd and 3 rd fingers. His feet showed the same findings as his sister's (case 5). The nose deviated slightly and had a wide bridge. Skull and hips were normal on $x$-ray.

Case $7(I \cdot 1)$, the proband's grandfather, underwent surgery in childhood for syndactyly between the 2 nd to 4 th fingers. The syndactyly was reported to extend up to the distal phalanges. The syndactyly on the feet was similar to that of cases 5 and 6 . We were unable to examine him.

\section{Discussion}

In Pfeiffer's syndrome the great variability of gene expression produces the following possible

*The shortening of the phalanges of the thumbs in cases 5 and 6 was proved by comparison with normal values of the relationship between the length of the 1st metacarpal and phalanges. ${ }^{3}$ 
manifestations in the thumbs and big toes: no alteration, ${ }^{2}$ shortening of the proximal or both phalanges (thumb, fig 2c, d; big toes, fig 3d), sometimes with deformity of the proximal phalanges (thumb, fig $2 a$, $\mathrm{b}$; big toes, fig 3a, c), and interphalangeal fusion (big toes, fig $3 \mathrm{~b}$ ). Only the feet show the presence of more extensive alteration of the first ray: widening (fig 3d) or bifurcation of the first metatarsal and the phalanges.

Acrocephaly is of varying types ${ }^{4}$ and is not always associated with craniosynostosis (fig 6a, b). It may appear in the most severe form as 'Kleeblattschädelanomalie', sometimes there are minimal changes (case 1), or it may not be present at all (cases 2, 4, and 6). No changes in the face are characteristic. Severe malformation or Crouzon's syndrome alone may be found, ${ }^{245}$ or the face may be normal (fig 4a, b).

Sporadic cases with only slight malformations or absence of some signs cannot be classified as Pfeiffer's syndrome.
The three abortions in family $W$ could be the result of the lethal gene combination. Abortions have been observed several times in Pfeiffer's syndrome. ${ }^{4}$

\section{References}

1 Pfeiffer RA. Dominant erbliche Akrozephalosyndaktylie. Z Kinderheilkd 1964;90:301-20.

2 Sanchez JN, de Negrotti TC. Variable expression in Pfeiffer syndrome. J Med Genet 1981 ;18:73-5.

3 Poznanski AK, Garn SM, Holt JF. The thumb in the congenital malformation syndromes. Radiology 1971; 100:115-29.

4 Cohen MM. An etiologic and nosologic overview of craniosynostosis syndromes. Birth Defects 1975;11: 137-89.

5 Escobar V, Bixler D. On the classification of the acrocephalosyndactyly syndromes. Clin Genet 1977;12: 169-78.

Requests for reprints to Dr J Vaněk, Hôpital de Meftah, Wilaya Blida, Algeria. 